\title{
Causes of Failure of Students in Computer Programming Courses: The Teacher - Learner Perspective
}

\author{
Kofi Adu-Manu Sarpong \\ Valley View University \\ P.O. Box AF 595 \\ Adentan-Accra, Ghana
}

\author{
John Kingsley Arthur \\ Valley View University \\ P.O. Box AF 595 \\ Adentan-Accra, Ghana
}

\author{
Prince Yaw Owusu \\ Amoako \\ Valley View University \\ P.O. Box AF 595 \\ Adentan-Accra, Ghana
}

\begin{abstract}
There are many factors that influence the high rate of failure of students in computer programming courses. This paper focuses on the teaching methodologies and strategies that are implemented in teaching programming courses. This is a major factor for consideration; hence an investigation into the causes of failure of students in programming courses from the learner perspective with regard to the teaching methodology used by teachers to teach these courses is relevant. Programming courses form part of the core concentration areas for students especially studying Information Technology (IT) and Computer Science (CS) as an undergraduate degree program. Programming students are expected to demonstrate competencies in the principles of programming and logic that are being taught in the course; even though some of these concepts are highly abstract and complex.

Their opinions to the usefulness of the teaching methods being implemented in programming courses were sought for. The needs and concerns about the teaching methods are highlighted in the survey and discussed thereby leading to the making of suggestions about the ways to improve the teaching methods that are used in computer programming courses in order to improve understanding of programming, when studied by students thereby minimizing failure rates.
\end{abstract}

\section{General Terms}

Information Technology, Computer Science, Programming

\section{Keywords}

Computer programming, teaching methodology, minimizing failure, programming logic

\section{INTRODUCTION}

Programming is an art and it requires the individuals' ability to interpret challenges into solutions. Computer Science (CS) and Information Technology (IT) students are required to take several programming courses as structured in their four year program. In their early years of studies they are required to study programming. The art of programming includes knowledge of programming tools and languages, problemsolving skills, and effective strategies for program design and implementation [1].

Computer programming is part and parcel of the computer science and its related programmes in education. It is an essential skill that must be mastered by anyone interested in studying computer science. Normally, in teaching computer programming, students will first be introduced to the concept of programming and data structure where they are taught on how to analyze problems, use specific techniques to represent the problem solution and validate the solution [2]. Computer programming courses are a part of many universities' curriculums and among the most important subjects for computer science students [3] as well as information technology students.

In the case of Valley View University (VVU), programming using $\mathrm{C}++$ is first taught at the first semester and programming using Java in the second semester of the first year. This paper studies the causes of student failure in programming courses of one hundred (100) students taking CS/IT undergraduate programmes at VVU, in the 2012-2013 academic years. The aim of the study was to understand why so many fail this course, and do not pass on to the second semester or the second year to take other advance programming courses. First year IT/CS students face a wide variety of challenges. Not only must they contend with the pressures of commencing tertiary education, with all the issues associated with adjusting from high school to university study, they also are confronted with immersing themselves into a discipline in which they may not have had any prior formal education and for which they must essentially learn a new language, a programming language [4].

The level of confusion in the minds of these students is noticeable when some of the fundamental concepts are taught in class. High rate of failure in programming occurs during the early years of their studies and this has been the trend over the years and this make programming courses look difficult in VVU and other universities in Ghana. The challenging nature of the course boils down to the fact that a strong practical component is required for the working environment. Therefore, hands on experience are needed even if one chooses not build a total career out of it. To effectively communicate with the software development team, a fair understanding of programming is required.

Computer programming is among the most challenging subjects in computer science curriculum, and the one that many students find difficult to grasp, hence it is very important to select an appropriate teaching strategy that will provide students with the most efficient learning environment [3]. Several research works has looked at the major causes of failure by students in programming. According to ([5], [6]) as cited by [3], researchers agree to the fact that learning to program presents a challenge for many students, and that many of them find programming concepts difficult to grasp.

\section{STATEMENT OF PROBLEM}

The goal in teaching computer programming is to develop in students the capabilities required of a professional software developer. Beginner programmers suffer from a wide range of difficulties [7]. Students' difficulty in computer programming 
is not unique to only Ghanaian students (i.e. specific to VVU IT/CS students only) but spans across most universities in Ghana and other parts of the world. Research works conducted about failures in programming courses have most often focused on the inability or the weakness of the student to understand the concepts. Many of these students find programming to be difficult and disheartening especially when they are beginners and even when they take advanced programming courses. Since programming is the basic skill required of computer programmers, the negative impact of these basic introductory courses may have harmful consequences in the learners' attitude towards the field [2]. Several problems identified by many authors ([2], [4]) are in the following categories:

- Weaker student admitted to pursue CS/IT

- Lack of problem-solving skills

- Lack of analytical thinking skills

- Lack of logical and reasoning skills

- Lack of programming planning

- Lack of programming conceptual understanding

- Lack of algorithmic skills

- The conceptual difficulty of various elements of the curriculum,

- The level of feedback that is available to students with regard to various components of the programming task,

- How patterns of study, namely low levels of faceto-face contact experienced by independent learners, impact on the first two issues.

Considering the challenge that computer programming represents to the students, we can assume that finding and implementing an appropriate teaching strategy will be one of the crucial factors in students' success in mastering the course content [3]. The method and strategy adapted by teachers contribute to the failure rate of students in computer programming. Therefore, the problem that has not been critically looked at is the teaching methodology employed by teachers of computer programming courses offered at the undergraduate level. The style adopted in teaching can affect the learners' performance.

\section{OBJECTIVES}

The main objective of this research is to investigate the teaching methods adopted by teachers of computer programming in Ghana. To assess the teaching methodologies, a survey was conducted to identify the best teaching practices that would enhance the teaching of programming courses and reduce the fear factor of students and also to improve the teaching environment in order to create a serene atmosphere for learning. The findings present the best teaching strategies and methodologies to improve the learning process of the students as the teacher adapts these strategies and methods.

\section{METHODOLOGY}

\subsection{Participants}

The survey was done by collecting data from students taking programming courses with the use of questionnaires. This method helped in soliciting their views regarding the teaching methods and strategies teachers use in teaching programming and how they adapt to it. Three hundred and fifteen (315) students make up the population at the Institute of Computer Science of VVU. Out of the population of three hundred and fifteen (315) students, a sample size of one hundred (100) participants was selected to respond to the questions in order to test sample instead of the entire population. The researchers took into consideration students who have taken one programming course or the other. They were largely drawn from second, third and fourth year. Among them were students who had either failed the course and are repeating and those who have taken programming courses and have successfully passed. 25\% were fourth year students, $44 \%$ comprised of third year students and the remaining $31 \%$ were in their second year.

Data was also collected by interviewing three expert lecturers in computer science field with regards to the teaching methods and strategies they currently adapt in teaching programming students. A procedure to extract information on the subject matter was designed to serve as a guideline during the interview sessions. Participation was optional. The lecturers selected to participate in the interview process was selected based on the number of years of experience in teaching IT/CS programming courses and their academic background. They hold masters degree in Software Engineering, Computer Science and Computer Engineering. The first lecturer has ten (10) years of teaching experiencing in computer programming and the second and third has six (6) and seven (7) years of experience respectively. The lecturers teach various programming languages such as $\mathrm{C}++$, Java, and $\mathrm{C \#}$ and Lisp for developing artificial intelligence and expert system projects. The interview procedure was designed to elicit information with regards to the teaching method and strategy employed by these lecturers in teaching programming and to find out from these experts the best teaching methods and strategies that can be adapted to minimize the failure rate of programming students.

\subsection{Materials and Procedures}

A questionnaire was given to each of the participants at the various levels and the researchers explained to them the meaning of some of the methods and strategies since the participants were not familiar with all of them. The questions posed were, "Which of the following teaching methodologies are the most effective in teaching programming to increase knowledge acquisition and understanding?" Individuals were asked to rank eight (8) teaching methods in order of effectiveness. The other question was: "which of these teaching strategies are appropriate for teaching programming to improve the learner's success rate and enhance the skill of learners?" Eight (8) teaching strategies were ranked by the individuals' in order of appropriateness. The response was inputted into Statistical Package for Social Sciences (SPSS) to analyse the data. 


\section{RESULTS/DISCUSSIONS}

The findings are discussed in this section based on the teaching methods and strategies identified. The methods and strategies are listed in table 1 and the discussions are based on these methods and strategies that when adapted will enhance the learning of programming and the success rate.

The experts interviewed categorized the causes of failure into four main areas. These recommendations calls for much attention, hence different research has been conducted to obtain the best possible solutions for some of the problems. They identified problems by the experts are:

1. Background, Field of Study and Teachers Methodology

2. Instructional materials, Teacher competence and interactivity

3. Teaching methods

4. Teaching strategies

Based on the problems identified by the experts, this research focuses on the third and fourth problems. The first and second problems will be conducted as separate research in future by the researchers.

\subsection{Experts view on Problem 3}

The experts believe that the reason why there is lack of skills on the part of students in solving and analyzing problems in programming is as a result of the poor teaching methodology adapted by programming lecturers. All the three lecturers interviewed agreed that the causes of failure in computer programming courses are highly due to the method adapted by teachers of programming. The techniques used by them in the problem representation are not effective. They said that teachers of programming do not employ multiple teaching methods in teaching programming courses. They said that most students lack the understanding of concepts in major topics in programming due to the style/method of teaching. Some teachers only adapt the lecturing method; others project approach, some tutorials, etc. The method either make the course easy to understand or difficult to understand. They believe that most teachers do not consider the background of the students into consideration when teaching programming. They also said that some teachers of programming teach only the theoretical aspect of programming neglecting the practical aspects that will provide the student the necessary skill. Two of the experts said that, they are unable to adapt the problem solving approach since the number of computers to student ratio do not measure up to the international standard of assigning computers to students. This does not expose the students enough to acquire the requisite skill to enhance their chances of success in programming. They also believed that, lack of programming projects affects the performance of the student.

In solving this problem, the experts believe that teachers of programming must adapt more than one teaching method to improve their teaching in programming courses to increase the skill and thinking capacity of the student.

\subsection{Expert View on Problem 4}

Programming is made challenging if the teaching strategy adapted by lecturers' is inappropriate and ineffective. Students find it difficult to understand programming concepts and coding principles (e.g. especially debugging) due to the type of teaching strategies lecturers use in teaching and thus contribute to the confusion students and become a possible cause of failure. They said that some of the lecturers adapts to explicit teaching, command style teaching, teaching by task and many more. One of the experts agreed that he initially adapted the explicit teaching strategy to teach his students programming. He aimed at teaching specific knowledge and skills and provided the necessary tools to assist the students in a particular study topic area to enable them understand the concepts. He agreed that the strategy is appropriate but does not provide the student the full understanding of the procedures and concepts.

The other two experts largely adapted puzzle-based teaching. They aimed at teaching students critical thinking and problem solving techniques. They believed using this approach equips learners with the ability to think through the syntaxes in both procedural and object oriented programming languages and they are able to apply these techniques in solving problems. In solving this problem, all the three experts invariably agreed to the fact that the teaching strategy adapted by computer programming teachers should be multifaceted. Adapting multiple teaching methods enhances the success rate of the students and builds their confidence and skills. Though the experts agreed to the fact that sending programming students on field trips was a good approach to expose students to expand their horizon in programming, none of them employed this method in teaching programming. In order to assist the learners improve and strengthen their problem solving skills and sharpen their knowledge on the syntax of the languages taught, teachers must adapt methods, techniques and strategies that will be applicable in teaching the paradigms and the content.

\subsection{Discussions of Methods and Strategies}

For the purposes of improving the performance of learners in programming courses, a list of teaching methods and strategies teachers use were rated by students who have taken one or more programming courses at school. To improve on the success rate of the learner, sixteen (16) factors comprising of teaching methods and strategies was listed for the learners to rank in order of effectiveness and appropriateness. Table 1 shows the methods and strategies listed for ranking by learners.

Table 1: Teaching methods and strategies

\begin{tabular}{|l|l|}
\hline \multicolumn{1}{|c|}{ Methods } & \multicolumn{1}{c|}{ Strategies } \\
\hline Lectures & Explicit teaching \\
\hline Laboratory practice & Command style teaching \\
\hline Projects & Teaching by task \\
\hline e-learning & Problem solving teaching \\
\hline Seminars and tutorials & Pre-recorded lectures \\
\hline Field trips & Puzzled-based learning \\
\hline $\begin{array}{l}\text { Continuous assessment and } \\
\text { examinations }\end{array}$ & Pair/group programming \\
\hline Problem based teaching & Peer tutoring \\
\hline
\end{tabular}




\subsection{Findings on teaching methods}

Among the teaching methods listed in table 1, it could be realized that the learners rated the most effective methods which when adapted will enable them improve on their skills as compared to the least effective methods. From the responses provided by the respondents, we subdivided the level of effectiveness into two (most effective - slightly effective is considered as one subdivision and generally effective - not effective as the other subdivision) for the analysis.

\subsubsection{Laboratory Practice}

A large number of the participants agreed that to better understand the concepts learnt and improve success rate of computer programming, more time should be spent working with the student at the laboratory. They therefore ranked laboratory lectures as the first method among the eight methods in order of effectiveness. $88 \%$ of the participants agreed that laboratory practice is the most effective teaching method for teaching programming. Only $12 \%$ disagreed to this fact. This exposes the learner to write up programs and apply the concepts learnt from teachers.

\subsubsection{Projects}

The participants believe that when lots of projects are given to learners in programming courses, it enhances their understanding of concepts and sharpens their skills in the course. This means that if teachers will actively engage students to improve their learning of programming course, then they are to engage the students with many practical projects. $74 \%$ of the students ranked this as the second most effective method that can be applied in teaching computer programming. Although $26 \%$ of the respondents had different opinion, the majority are in favour and are of the view that it is the most second of effective teaching method.

\subsubsection{Lectures}

To improve the performance of learners in programming, learners were asked to rank among other teaching methods the effectiveness of teachers' lecturing programming and its impact on their passing rate. This was ranked third to projects in terms of enhancing learners' success rate. A considerable number of the students $(65 \%)$ agreed unanimously that lectures are an effective method for teaching programming. On the contrary, the remaining 35\% somewhat disagree or were not in agreement whether lecturing affects their performance or not. In this regard, it could be emphasized that teachers of programming courses are encouraged to adapt this method. The unanswered question with respect to the size of the class remains answered? What will be the impact of lectures on the success rate of students in the programming environment when the class size is large? Other factors that suffice in terms this method being effective method of teaching programming courses to reduce the failure rate and to improve on success are teachers insuring that learners actively participate in lectures and ensure effective completion of all aspects of course.

\subsection{Effectiveness of other teaching methods}

The participants ranked seminars and tutorials and problembased teaching as fourth and fifth respectively. $63 \%$ of the participants believe seminars and tutorials are good methods to enhance effective teaching of programming whereas $37 \%$ think otherwise. On the other hand, $56 \%$ also believe that problem-based teaching which aims at engaging students to solving problems whiles teaching is a good option that can be considered by teachers of programming courses whereas $44 \%$ of the participants think otherwise.

\subsection{Ineffective teaching methods}

Field trips, e-learning and continuous assessment and examinations (CAE) were ranked sixth, seventh and eighth respectively. Most of the participants believe that these methods are not very effective when it comes to teaching programming courses. $72 \%$ of the participants were of the opinion that CAE are not the best methods for teachers to use when teaching programming courses. When all the focus is put on the assessment and examinations, students believe that it makes them study for examination purposes only without acquiring the skills for hands-on activities. On the contrary, $28 \%$ have a different opinion. About $65 \%$ of the participants are of the view that e-learning is not an effective method of teaching programming. Due to the level of difficulty of programming courses, this method will not enhance the understanding of concepts and syntax to the learner. Although $35 \%$ of the respondents have a different view, it is obvious that the majority of participants think otherwise. Moreover, $46 \%$ are of the opinion that if students are sent on field trips to experience programming in organizations it will expose them to the practical projects and improve their learning outcomes. But greater number of the participants $(54 \%)$ has a different view.

\subsection{Findings on teaching strategies}

From the findings, eight different teaching strategies were provided for the participants to rank in order of appropriateness. Reference [10] explains these strategies. Explicit teaching aims at teaching specific knowledge and skills by providing tools to assist students in a particular study area, command style teaching aims at teachers being the sole authoritarian and students are to comply with the commands initiated by the teacher, teaching by task aims at allowing students to develop at their own rate and direction and take responsibility for their own learning, problem-based teaching aims at students engagement for problem solving, prerecorded lectures aims at using recorded lessons in class whereas puzzled-based teaching aims at teaching students critical thinking and problem solving techniques and pair/group programming aims at students working side by side on concepts taught.

Reference [8] explains peer tutoring as the system of instruction in which learners help each other and learn by teaching. It is beneficial in helping students learn actively in a setting that promotes multiple-intelligences as cited in [9]. It is one of the most effective methods in promoting studentcentred learning. According to [9] peer tutoring aims at students teaching other colleagues. Learners understood these teaching strategies and gave their candid opinions on the most appropriate strategy to be used in the teaching of programming courses to enhance the skill of the learner as well as reducing the failure rate based on their experiences. Following the teaching method concerns, $82 \%$ of the participants indicated that one of the most appropriate strategies to be adapted for teaching programming courses is the problem-based teaching. The next strategy ranked second in the order of appropriateness as indicated by $79 \%$ of the 
participants is pair/group programming approach. They believe that the lecturer should engage and encourage group programming since it promotes team work and also increase the participatory level of all learners. On the scale of preference, the participants ranked peer tutoring as the third appropriate strategy that could be adapted by teachers of programming to improve the skill of learners and also to reduce the high failure rate. $69 \%$ of the participants believe that a student teaching a colleague student can be effective and it should be encouraged.

\subsection{Inappropriate teaching strategies}

The participants indicated that command style teaching (77\%) used by some teachers of programming affects the performance and it should not encouraged. Programming courses are difficult and the syntax is cumbersome to comprehend so it the teacher becomes the sole authoritarian and does not involve the learner it may worsen the case. Most of the participants also were of the view that pre-recorded lectures $(69 \%)$ are not very appropriate to be adapted to teach programming courses. Learners might not have the opportunity to understand the syntactical rules of the language being taught. A little over $50 \%$ of the participant agreed that explicit teaching, puzzled-based teaching and teaching by task are appropriate whereas almost $50 \%$ also are of different view.

The participants ranked the methods of teaching and the teaching strategies in reference to the most effective teaching method to least (Laboratory practice, Projects, Lectures Seminars and tutorials, Problem-based teaching, Field trips, E-learning, Continuous Assessment and Examination) and the most appropriate to the least appropriate (Command style teaching, Pair/group programming, Peer tutoring, Puzzledbased learning, Teaching by task, Explicit teaching, Prerecorded lectures and Problem solving teaching) respectively. In the case of the teaching methods, participants believe that teaching by laboratory practice engagement is the most effective and the least effective teaching method is continuous assessment and examinations. The emphasis should be placed on the acquisition of skill that will put the learner above all odds. It turned out that most of the respondents were of the view for them to have the required skill and pass their programming courses; they are expecting their teachers to adapt a teaching method in which most of the time will be dedicated to laboratory practice and projects.

These approaches will enhance teaching and learning of programming courses. According to [11], these methods aim to improve students' success rate by increasing their motivation and encourages the greater self-engagement, not only in assignments provided within the course, but also in further exploration of programming challenges outside the assignments' boundaries.

\section{Discussions/Conclusions}

From the analyses of the methods and strategies, the main problems identified by the experts who were interviewed and the survey conducted, it has been realized that aside the numerous causes of failure by students' in programming courses discussed above, we cannot overlook the teaching methods and strategies since these factors are major contributing factors to the high rate of failure of computer programming students. Computer programming is among the most challenging subjects in computer science curriculum, and the one that many find difficult to grasp, hence it is very important to select an appropriate teaching strategy that will provide students with the most efficient learning environment [11].

Reference [12] illustrates a teaching strategy adapted by a teacher of C++ Programming. It was realized that, the author adapted this strategy due to the long years (about 20 years) of teaching programming. The author though concentrated on first year programming students adapts this strategy in order to improve the performance. First of all, concepts are discussed; sample programs are given and other related activities. Following the discussed lessons, students are vigorously engaged in Lab Work, which is the laboratory practice to test their understanding on the concepts presented. This and other assignments expose the students' different problem solving techniques and establish the students understanding to the steps involved in programming.

To also establish the fact laboratory practice is a key factor when it comes to teaching methods, [13] developed a laboratory-based model for computer science instruction. Their model included three components: an online course builder for the instructor, a Web-based learning environment for the delivery of all student activities, and a course portal that served as a learning management system. The evaluation of the system showed that student performance in the course had improved and that the students found the course enjoyable.

To improve on the teaching methods discussed above, the following have been outlined: a curriculum basedprogramming that focuses on concepts rather than paradigms, the adoption of analogy in teaching programming, assessment (objective testing and performance based assessment although from the survey most of the participants ranked this as the eighth on the scale of eight.), but the researchers suggest that in the performance-based category, assessment such as laboratory exercise, programming assignments and examinations help to test students' ability to write working programs, the participants in this exercise are of a different view [14]. Therefore we can infer that this factor might be environmental dependent and must be relooked at.

To this point, we have realized that there exist a teaching method and strategy that when adapted for the teaching of computer programming courses, both teachers and learners will enjoy the course and high performance achieved as a result of the right method and approach that was adapted. Teachers should adapt the method that will able him teach concepts for the students to understand and use the right tools such as flowcharts and algorithms in order to help the students grasp the ideas that are relayed from the teacher to the learner. One approach adapted by the one of the researcher's at the time the research was conduct was combination of two or more methods and strategies. For example any programming challenge given to the student, they were expected the walk through the following (identification of problem, analysis (input, processing and output), design (algorithms and flowcharts) and then coding). This method allows the learner to bring out the understanding before going to the coding since direct coding in computer programming mostly confuses the learner.

To improve teaching and learning of computer programming courses, we recommend to teachers to adapt more than one method or strategy in their instructional process. 
For learners to acquire hands-on skills in programming, teachers are requested to combine laboratory practice sessions, projects, seminar and tutorials along with lectures in order to encourage students to have several opportunities and to adapt to the best practice. This is in agreement to the findings of [14] which states that; teachers' task is to select an appropriate teaching method or blend of methods. Out of the eight proposed methods, a teacher can adapt any of the best approach would best suit his teaching environment.

On the other hand, more than one teaching strategy should be adapt for teaching programming, we recommend that teachers adapt peer tutoring, pair/group programming and problem solving teaching strategies to give learners better opportunities to interact with their peers and teachers. Most participants believe that adapting one of these methods or one of these strategies makes programming very challenging and frustrating. We conclude that programming lecturers should adapt effective teaching methods and appropriate teaching strategies in teaching computer programming courses that will encourage more students to work hard and become highly skilled programmers. This will mean that there will be an increase in programmers and many real time applications will be developed to solve problems. No information was collected on age, gender, academic discipline of participants as the research focus was teaching methods and strategies; however, future studies may expand on existing knowledge by identifying connections between these factors and teaching methods and strategies adopted by teachers' to enhance programming in order to increase student success rate and skills development.

\section{ACKNOWLEDGMENTS}

We express our thanks to the Almighty God for His directions and our dear families who supported us throughout the night whilst we worked tirelessly to achieve this successful paper.

\section{REFERENCES}

[1] Kirsti Ala-Mutka, "Problems in learning and teaching programming," a literature study for developing visualizations in the Codewitz-Minerva project,pp. 1 13 , (n.d)

[2] M. N. ISMAIL, N. A. NGAH and I. N. UMAR, "Instructional strategy in the teaching of computer programming: a need assessment analyses," TOJET: The Turkish Online Journal of Educational Technology, volume 9 Issue 2, pp. 569-571, April 2010.
[3] S. Mohorovicic and V. Strcic, "An Overview of Computer Programming Teaching Methods," pp. $1-6$, (n.d).

[4] M. Butler and M. Morgan, "Learning challenges faced by novice programming students studying high level and low feedback concepts," Proceedings ascilite Singapore, pp. $99-107,2007$.

[5] T. Jenkins, "On the Difficulty of Learning to Program," Proceedings of the 3rd Annual Conference of the LTSN Centre for Information and Computer Sciences, Loughborough, UK, pp. 53-58, 2002.

[6] Wiedenbeck S, LaBelle D, Kain V N R, "Factors Affecting Course Outcomes in Introductory Programming," Proceedings of the 16th Workshop on Psychology of Programming, pp. 97-109, 2004.

[7] D. Nandigam and H. Bathula, "Competing Dichotomies in Teaching Computer Programming to BeginnerStudents," pp. 1- 9, December 2011.

[8] Goodlad, S. and Hirst, B., "Peer tutoring: a guide to learning by teaching” London: Kogan, 1989

[9] $\mathrm{Hu}$ Xiaohui, "Improving teaching in Computer Programming by adopting student-centred learning strategies", The China Papers, pp. 47 - 48, November 2006.

[10] (2013) The Flinders website. [Online]. Available: http://ehlt.flinders.edu.au/education/DLiT/2004/13DLT/ ExplicitTeach.htm

[11] Sanja Mohorovičić and Vedran Strčić, "An Overview of Computer Programming Teaching Methods," pg. 1 -6, n.d.

[12] (2013) The Mathbits website. [Online]. Available: http://mathbits.com/MathBits/CompSci/Strategies.htm

[13] Clancy, M., Titteron, N., Ryan, C., Slotta, J., \& Linn, M., "New roles for students, instructors, and computers in a lab-based introductory programming course." Proceedings of the 34th SIGCSE Technical Symposium on Computer Science Education, pp. 132-136, 2003.

[14] Iwona Miliszewska and Grace Tan. (2007). "Befriending Computer Programming: A Proposed Approach to Teaching Introductory Programming.", Issues in Informing Science and Information Technology Volume 4, pp. $277-287$ 